\title{
Research on the Effect of "Work-life Balance" on Fertility Intention of Child-bearing Age Population
}

\author{
Meiduo Zhou $^{1}, \mathrm{Xu}_{\mathrm{Zhao}}{ }^{1, *}$ and Ziyi Dong ${ }^{1}$ \\ ${ }^{1}$ School of Public Affairs and Administration, University of Electronic Science and Technology of China, Chengdu, \\ Sichuan 611731, Chinas \\ *Corresponding author. Email: 201921160314@std.uestc.edu.cn
}

\begin{abstract}
As fertility attitude changes and medical technology advances, the birth rate has dropped and the life expectancy of the elderly has increased, China is experiencing a period of "fewer children and younger age" like other developed countries. At the same time, most of the childbearing age group will participate in the labour market competition and face the problem of work-life balance. Therefore, based on the data of the research group "Population Fertility and Public Services", then established a regression model to explore the impact of "work-life balance" on the childbearing willingness of the childbearing age population, finally found that: the current situation of "work-life balance" is positively related to the fertility willingness, while in the expected difficulty of "work-life balance" (opportunity cost) dimension, the opportunity cost of reemployment and the opportunity cost of career development is negatively related to the fertility willingness. Therefore, in order to improve the fertility willingness of the population of childbearing age, the government should play a practical role in improving the market of child care and strengthening the role of the intergenerational upbringing of families, so as to reduce the parenting pressure of families, especially professional women, and improve the fertility willingness.
\end{abstract}

Keywords: fertility intention; work-life balance; fertility policy; childbearing age population

\section{INTRODUCTION}

The rapid development of economy and society, the progress of modern concept and medical technology have brought about the change of fertility attitudes and the extension of life expectancy of the elderly population. Like most developed countries in the world, China is now experiencing the stage of "fewer children and younger age". According to data from the seventh national census, compared with the sixth national census, the population aged 60 and above has increased by 5.44 percentage points, the population aged $15-59$ has decreased by 6.79 percentage points, and the population aged 0-14 has increased by 1.35 percentage points over the past 10 years. The demographic dividend accumulated by the "universal two-child" policy has been fully released, but the aging process is further deepened and the fertility rate continues to decrease. In 2020, the total fertility rate of China is only 1.3 , lower than $2.1^{[1]}$, which is the level of maintaining the generation replacement. Therefore, the country releases the "three-child" policy in 2021 to stimulate the fertility willingness of the population at childbearing age. But getting back to generational levels is still a difficult process. On the basis of reading previous literatures, it is found that most scholars discuss fertility willingness from the perspective of economic cost and family support, while the research of "work-life balance" on fertility willingness is slightly weak. Therefore, from the perspective of "work- life balance", this paper discusses the influence of worklife balance on the fertility intention of the childbearing age population. Individuals play multiple roles at the same time, among which work and family roles are the two most important roles, but the conflict between roles may lead to work-life conflict or life-work conflict. Therefore, it is of great significance to coordinate the relationship between the two roles and rationally allocate time resources to improve the fertility willingness of the population at childbearing age and delay the aging process.

\section{LITERATURE REVIEW}

Economic factors are the fundamental reason for the change of fertility intention. Xizhe Peng et al. (2015) believes that fertility cost has become an important influencing factor when families choose to have children ${ }^{[2]}$. Lin Feng (2020) looked through the previous literature and related theoretical design of the questionnaire and 2018 National Statistical Yearbook, and researched the fertility intension through the hierarchical model from the microlevel and macro-level. The results show that the factors of regional economic development level and the supporting factors of fertility policy have a significant impact on the family of childbearing age in China. ${ }^{[3]}$ Shengli Chen and Shikun Zhang also believe that economic factors have the most significant effect on the fertility willingness of the population of childbearing age, and that the level of economic development in a region is the most fundamental 
factor influencing the fertility willingness of the population of childbearing age in that region ${ }^{[4]}$. Yingtan $\mathrm{Mu}$ and Xin Yuan (2018) believe that the social culture of traditional altruism has changed, and people are no longer inclined to the idea that more children means more happiness. In order to improve the fertility level, we should pay attention to the influence of fertility cultural factors and build up the idea that children are public goods. The state, society and family should jointly bear the cost of raising children ${ }^{[5]}$.

From the perspective of research content, those have been studied by scholars focus on the impact of certain factors on fertility intention, such as economic cost and family support. There are few literatures on the influence of "work-life balance" on fertility intention, so the research in this paper can make a beneficial supplement to some extent.

\section{THEORETICAL HYPOTHESIS AND THEORETICAL MODEL}

\subsection{Research Framework and Data Sources}

In the past, scholars divided work-life balance into time balance, engagement balance and satisfaction balance. In this paper, we propose a new dimension to measure worklife balance, namely, the status quo of work-life balance and the expected work-life balance, namely, the opportunity cost dimension. The reason for choosing the expected "work-life balance", i.e. opportunity cost dimension, is that the respondents of this questionnaire are all the population of childbearing age in the period of career development, and their feelings of work-life conflict are more clear. Especially for professional women, childbirth may lead to "depreciation" of labour capital, "gender discrimination" and "income punishment" in the labour market and even lead to the interruption of career development and other problems. In addition, women, as fertility subjects, play an important role in family fertility decisions due to their special physiological characteristics, and the conflict between work roles and family roles may lead them to choose late childbearing when making fertility choices. Therefore, this paper explains the opportunity cost dimension through two aspects: opportunity cost of reemployment and opportunity cost of career development. The data in this paper comes from the database of the "Population Fertility and Public Services" project group which constructed by the research team of Associate Professor Meiduo Zhou, the main contents of the questionnaire are the individual and family characteristics (sex, age, income, occupation type, education level, marital status, family population, etc.), fertility intention and the measurement of related variables of work-life balance.

\subsection{Variable Definition and Measurement}

The fertility intention in this paper is replaced by the ideal number of children, that is, "Without considering any limiting factors, your ideal number of children is". In the questionnaire setting, the options for the ideal number of children are: $0,1,2,3,3$ and above. When using spss 22.0 software for data entry, use 1 instead of 0 ideal number of children, use 2 instead of 1 ideal number of children, substitute 3 for 2 ideal children and 4 for 3 ideal children, replace 4 ideal children with 5 (for the convenience of variable calculation and follow-up study, options: the ideal number of three or more children is considered as the ideal number of four in this paper).

The core explanatory variables of this paper are: current work-life balance and the expected work-life balance that is the opportunity cost. In terms of "work-life balance", the respondents evaluated the individual's current working and life status subjectively: completely unable to balance code for 1 , less able to code for 2 , can code for 3 , can better balance code for 4 , can completely balance coded for five. The opportunity cost is measured from two aspects: the first is the opportunity cost of re-employment, that is, the opportunity cost required by the respondents to re-enter the workplace after having children: no difficulty code for 1 ; It's a little bit harder to code 2; It is difficult to code 3; It's very difficult to code 4 . The second is the opportunity cost of career development, that is, the opportunity cost generated by childbirth on personal career development: no Impact Code 1; a Little Impact Code 2; a big impact Code 3; a very big impact code 4 .

In this paper, gender, age, individual annual income and educational background were set as control variables. When the gender variable was entered into spss22.0, the male code was 1 and the female code was 2 .

\subsection{Research Hypothesis and Theoretical Model}

Due to the irreconcilable conflict between the roles of work and family life, and the limited time experience of individuals, playing one role may squeeze the time of another, thus causing conflicts. In this paper, the "work-life balance" survey is a subjective choice made by the respondents on the individual work-life status. Tingting Liu (2018) used logistics regression analysis to explore the impact of work-family conflict and social support on fertility intention by taking 2,448 women of childbearing age who have had a child in 12 cities across China as samples. Studies have found that work-family conflict can weaken the fertility willingness of professional women of childbearing age ${ }^{[6]}$. Based on the above research, this paper proposes the following hypothesis:

Hypothesis 1: "work-life balance" has a significant positive effect on fertility intention.

Opportunity cost refers to the opportunity cost of reemployment and career development after childbirth in the labour market. In this paper, we use the opportunity cost of 
re-employment and career development to explain it. The survey found that in the past three years, $20.6 \%$ of the units where high-level talents work have the situation of "only hiring men or giving priority to men under the same conditions". $30.8 \%$ have shown that men are promoted faster than women under the same conditions; There are more men than women in highly skilled and promising jobs, with $47.0 \%$..Hui Feng (2018), based on the data of China General Social Survey (CGSS), established the comprehensive value index of women of childbearing age affected by childbearing policy to measure the easing of childbearing policy and measure the degree of gender discrimination in employment by measuring the degree of occupational segregation. The research results show that the increase of occupational isolation will significantly inhibit women's willingness to have children ${ }^{[7]}$. Jing Chen (2017) constructed the comprehensive influence value of fertility policy on women during their childbearing years through the micro-data of China General Social Survey (CGSS) from 2010 to 2013 and studied the correlation between fertility policy and female employment discrimination. The research found that occupational gender discrimination inhibited women's childbearing demand $^{[8]}$. Based on the above researches, this paper proposes the following hypothesis:

Hypothesis 2: Opportunity cost of re-employment and opportunity cost of career development have a significant negative impact on fertility intention.

In this paper, we investigated the effect of work-life balance on fertility intention by sequencing logit regression and the ideal number of children is used to measure the fertility intention. The ideal number of children in this paper is set with options of $0,1,2,3$ and above at different levels, so the sequential Logit model is mainly used for analysis. The functional form is as follows:

$$
\log \left(\frac{\mathrm{p}\left(\mathrm{p}_{i} \leq \mathrm{j}\right)}{1-\mathrm{p}_{\left(\mathrm{p}_{i} \leq \mathrm{j}\right)}}\right)=t_{j}-g x_{i}
$$

In the formula, $\mathrm{P}_{\mathrm{i}}$ represents the ideal number of children, $\mathrm{P}=1$ represents the ideal number of children is $0, \mathrm{P}=2$ represents the ideal number of children is 1 , and $\mathrm{P}=3$ represents the ideal number of children is 2 or more; $\mathrm{x}_{\mathrm{i}}$ represents the ith factor affecting the number of ideal children, $t_{j}$ as the model intercept, can be regarded as a constant term, and $\mathrm{g}$ is the independent variable coefficient.

\section{DESCRIPTIVE STATISTICAL ANALYSIS}

In Figure 1, on the question of "work-life balance", according to the results of the collected questionnaire, 61 people said that the work-life balance was completely unbalanced, accounting for $7.61 \% ; 247$ people chose not to be able to take care of family when working, accounting for $30.80 \%$; 384 people chose to be able to basically take care of family when working, accounting for $47.88 \%$; 76 people chose to be able to better take care of family when working, accounting for $9.48 \%$; 34 people chose complete work-life balance, accounting for $4.24 \%$. According to the results of the questionnaire, only $4.24 \%$ of the respondents said they had a complete balance between work and life, that is, most of the respondents said they had "work-life conflict".

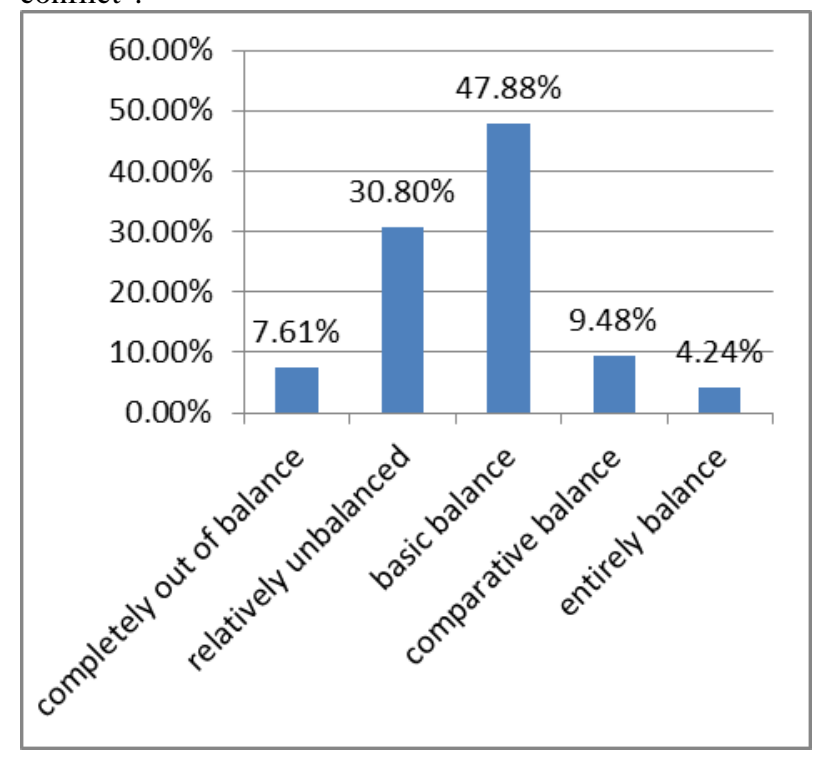

Figure 1. "Work-life balance"

In Figure 2, on the question of "difficulty of reemployment after childbirth", 116 people chose no difficulty, accounting for $14.46 \%$; 340 people had a little difficulty, accounting for $42.39 \%$; 265 people had great difficulty in choosing, accounting for $33.04 \%$; 81 people chose very difficult, accounting for $10.10 \%$. The question was set as: "What do you think if you work again after having children?" According to the questionnaire:85.53\% of the respondents said it was difficult to find a job after giving birth, and $43.14 \%$ of the respondents thought it was more difficult to find a job after giving birth. It indicates that childbearing has a heavy limit on career development. The respondents are of childbearing age, both male and female, and the impact of childbearing on men is lower. However, there are still $43.14 \%$ respondents who believe that it is very difficult to find a job again after having a child. This also proves that the current unfriendly fertility environment, especially for women. Women as the main body of fertility and traditional gender role division of labour on the solidification of women's role, raising children may bring career interruption or miss promotion, training and other human capital and indirect losses. 


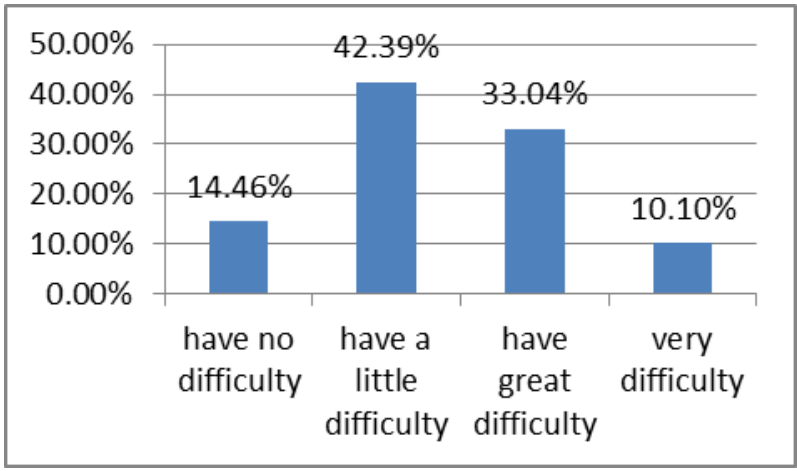

Figure 2. The opportunity cost of re-employment

In Figure 3, on the question of whether having children will affect career development, according to the recovery data, 116 people chose not to have any influence, accounting for $16.58 \%$; 380 people chose to have a little influence, accounting for $47.38 \%$; 224 people chose to have a great influence, accounting for $27.93 \%$; 65 people chose to have very great influence, accounting for $8.10 \%$. According to the survey data, $83.41 \%$ of the respondents said that having a baby would have an impact on their career development. Enterprises are generally believed that women after having a baby will spend more time and energy on their family and children; they cannot contribute more to the economic output of enterprises. In order to obtain more economic benefits, enterprises will assign women to jobs that are not demanding. And women's upward development will be hindered, which is called the "glass ceiling effect".

\begin{tabular}{|c|c|c|c|c|}
\hline \multirow{2}{*}{$\begin{array}{l}50.00 \% \\
40.00 \%\end{array}$} & \multicolumn{4}{|c|}{$47.38 \%$} \\
\hline & & & & \\
\hline $3000 \%$ & & & $27.93 \%$ & \\
\hline $2000 \%$ & $16.58 \%$ & & & \\
\hline & & & & $8.10 \%$ \\
\hline $10.00 \%$ & & & & \\
\hline & $\begin{array}{l}\text { have no } \\
\text { influence }\end{array}$ & $\begin{array}{c}\text { have a } \\
\text { little } \\
\text { influence }\end{array}$ & $\begin{array}{c}\text { have a } \\
\text { great } \\
\text { influence }\end{array}$ & $\begin{array}{c}\text { have very } \\
\text { great } \\
\text { influence }\end{array}$ \\
\hline
\end{tabular}

Figure 3. The opportunity cost of career development

\section{EMPIRICAL ANALYSIS}

According to Table 1, after controlling variables such as gender, age, individual annual income and educational background, "work-life balance" is positively correlated with fertility intention, that is, the higher the individual's "work-life" balance, the stronger his or her fertility intention. As a scarce resource, excessive allocation of time in one field will inevitably lead to the reduction of other fields, resulting in individuals' "work-life" conflict and negative impact on their fertility intention. Hypothesis 1 is partially true. From the perspective of opportunity cost analysis, the opportunity cost of re-employment is negatively correlated with fertility intention, and the opportunity cost of career development is negatively correlated with fertility intention. In other words, the higher the opportunity cost, the lower the fertility intention. The cost of fertility includes direct cost and indirect cost. Direct cost refers to the monetary expenditure generated by bearing and raising children. Indirect costs refer to the depreciation of human capital and even career interruption caused by missed training and promotion due to childbirth. Compared with direct costs, indirect costs have a greater impact on women. Therefore, the higher the opportunity cost of childbearing, the lower the fertility intention of people of childbearing age. Hypothesis 2 is partially true.

Table 1. Results of the Ordered Logit Regression of fertility intentions on the "work-life balance"

\begin{tabular}{|c|c|c|c|}
\hline & Mode1 & Mode2 & Mode3 \\
\hline Control variable & & & \\
\hline Sex & $-0.003 * *$ & $-0.003 * *$ & $-0.004 * *$ \\
\hline Age & $0.000 * * *$ & $0.000 * * *$ & $0.000 * * *$ \\
\hline $\begin{array}{l}\text { Individual Annual } \\
\text { Income }\end{array}$ & -0.55 & -0.52 & -0.558 \\
\hline $\begin{array}{c}\text { Education } \\
\text { background }\end{array}$ & $0.005 * *$ & $0.006 * *$ & $0.01 *$ \\
\hline $\begin{array}{l}\text { "Work-life } \\
\text { balance" }\end{array}$ & & 0.068 & \\
\hline $\begin{array}{c}\text { Opportunity cost } \\
\text { Opportunity cost } \\
\text { of re-employment } \\
\text { Opportunity cost } \\
\text { of career } \\
\text { development }\end{array}$ & & & $\begin{array}{l}-0.252 \\
-0.424\end{array}$ \\
\hline Adjusted $\mathrm{R}^{2}$ & 0.0193 & 0.0215 & 0.0227 \\
\hline
\end{tabular}

\section{CONCLUSION}

To maximize the release of fertility intention and increase the fertility rate, the country has successively introduced the "single two-child" policy, the "universal two-child" policy and the "three-child" policy. In terms of the fertility rate in recent years, the cumulative fertility effect of the "universal two-child" policy has been fully released. The born population reached the population peak of nearly a decade in 2016, but since then, it has been declining year by year, and the population blowout effect did not appear as expected by demographers, the "universal two-child" policy has been cooled down. Therefore, the country will lift the "three-child" policy in 2021, but according to the social response, the "three-child" policy is also faced with difficulties. In the final analysis, the liberalization of the fertility policy is only the liberalization of the number of births, and the related basic supporting fertility measures have not kept up with it. Fertility behaviour is restricted, and the fertility rate is difficult to increase. Therefore, 
based on the data of the research group "Population Fertility and Public Services", this paper discusses the influence of "work-life balance" on the fertility willingness of the childbearing age population. The results show that: the status of "work-life balance" positively affects the fertility willingness, that is, the more work-life balance an individual has, the higher the fertility willingness. In addition, in the analysis of the expected work-life balance, it is found that the opportunity cost of re-employment and the opportunity cost of career development negatively affect the fertility willingness, that is, the higher the opportunity cost, the lower the individual's fertility intention. And the relevant government departments need to make corresponding responses in what aspects, in order to improve the fertility of the population of childbearing age to make a beneficial supplement.

First, we should improve the market for childcare, and at the same time enhance intergenerational parenting to reduce the pressure on families. At present, the issue of childcare has always been a difficult problem plaguing Chinese families. As the responsibility subjects of both sides of the family participate in the labour market, childbirth is bound to have an impact on women's career and career development, and this work-family conflict is bound to hinder the desire to have children. Perfecting the market of childcare can effectively alleviate the problems of childbirth and childcare, especially the pressure of childcare of preschool families. In addition, with the improvement of medical and economic level, the life expectancy of the elderly population is extended, and the elderly population in China is increasing ${ }^{[9]}$. The role of intergenerational family rearing can be appropriately played to reduce the pressure of family rearing, especially the conflict of women's participation in the labour market. At the same time, due to the imperfection of the nursery market, intergenerational rearing can make up for the defects of the nursery market and relieve the pressure of family parenting.

Second, enhance the dissemination of reproductive culture. No matter the policy of "single child", "universal second child" or "third child", they only publicize the content of the policy itself, but lack of creating a good cultural atmosphere of childbirth in the society. Strengthen the popularization of the concept of childbearing, change the concept of childbearing formed since the implementation of the family planning policy, change people's concept of childbearing and family concept, and reshape cultural confidence.

\section{REFERENCES}

[1] Jihong Duan. Population law and population policy orientation of Socialism with Chinese characteristics: an analysis based on the effect of universal two-child policy [J]. Journal of Contemporary Economic Research, 2021(03):61-70.

[2] Xizhe Peng. The realization of the goal of the universal two-child policy requires a holistic package $[\mathrm{J}]$. Exploration, 2016(1)

[3] Lin Feng. Research on fertility intention of childbearing age families in China [D]. 2020.

[4] Shengli Chen, Shikun Zhang. Research on contemporary mate choice and fertility intention: survey on fertility intention of urban and rural residents in 2002 [M]. China Population Publishing House, 2003.

[5] Yingtan $\mathrm{Mu}$, Xin Yuan. The contradiction between "born" and "not born" -- family resources, cultural value or children's gender? [J]. Population, Research, 2018, 42(1):90-103. ]

[6] Tingting Liu. The impact of work-family conflict on the willingness of urban professional women to have a second child[J]. Hebei academic journal, 2018, 38(06):187-193+199.

[7] Hui Feng. Can women's fertility intention be improved? [D]. Zhejiang Gongshang University, 2019

[8] Jing Chen. Fertility policy occupational gender discrimination and fertility suppression [D]. Nanjing University, 2017.

[9] Yewen Yu, Liutang Gong. Fertility policy, fertility rate and family support for the elderly $[\mathrm{J}]$. China Industrial Economics, 2021(05):38-56. 